\title{
Belgian rare diseases plan in clinical pathology: identification of key biochemical diagnostic tests and establishment of reference laboratories and financing conditions
}

\author{
Nathalie M. Vandevelde ${ }^{1,2^{*}}$ (D) , Pieter Vermeersch ${ }^{2,3,4}$, Katrien M. J. Devreese ${ }^{2,5}$, Marie-Françoise Vincent ${ }^{2,6,7}$, \\ Béatrice Gulbis ${ }^{2,8}$, François Eyskens 9, 10,11, François Boemer 2,12, André Gothot ${ }^{2,13}$, Viviane O. Van Hoof 2,14, \\ Carolien Bonroy 2,5, Hedwig Stepman 2,5, Geert A. Martens 2,15,16 , Xavier Bossuyt 2,3 , Laurence Roosens 2,17, \\ Julie Smet ${ }^{8}$, Hilde Laeremans ${ }^{18}$, Ilse Weets ${ }^{2,19}$, Jean-Marc Minon ${ }^{20}$, Kris Vernelen ${ }^{1}$, Wim Coucke ${ }^{1}$ and Advisory \\ Board of the Action 1 of the Belgian National Plan for Rare Diseases
}

\begin{abstract}
Background: One objective of the Belgian Rare Diseases plan is to improve patients' management using phenotypic tests and, more specifically, the access to those tests by identifying the biochemical analyses used for rare diseases, developing new financing conditions and establishing reference laboratories.

Methods: A feasibility study was performed from May 2015 until August 2016 in order to select the financeable biochemical analyses, and, among them, those that should be performed by reference laboratories. This selection was based on an inventory of analyses used for rare diseases and a survey addressed to the Belgian laboratories of clinical pathology (investigating the annual analytical costs, volumes, turnaround times and the tests unavailable in Belgium and outsourced abroad). A proposal of financeable analyses, financing modalities, reference laboratories' scope and budget estimation was developed and submitted to the Belgian healthcare authorities. After its approval in December 2016, the implementation phase took place from January 2017 until December 2019.

Results: In 2019, new reimbursement conditions have been published for 46 analyses and eighteen reference laboratories have been recognized. Collaborations have also been developed with 5 foreign laboratories in order to organize the outsourcing and financing of 9 analyses unavailable in Belgium.

Conclusions: In the context of clinical pathology and rare diseases, this initiative enabled to identify unreimbursed analyses and to meet the most crucial financial needs. It also contributed to improve patients' management by establishing Belgian reference laboratories and foreign referral laboratories for highly-specific analyses and a permanent surveillance, quality and financing framework for those tests.
\end{abstract}

Keywords: Rare diseases, Clinical pathology, Financing, Reference laboratories, Reimbursement codes, Expertise

*Correspondence: nathalie.vandevelde@sciensano.be

1 Department of Quality of Laboratories, Sciensano, Rue Juliette Wytsmanstraat 14, 1050 Brussels, Belgium

Full list of author information is available at the end of the article

\section{Introduction}

In Europe, rare diseases are defined as disorders affecting less than 1 patient in 2.000 individuals $[1,2]$. To this date, approximately 8.000 rare diseases have been identified [2-5]. Their diagnosis is often delayed because of original author(s) and the source, provide a link to the Creative Commons licence, and indicate if changes were made. The images or other third party material in this article are included in the article's Creative Commons licence, unless indicated otherwise in a credit line to the material. If material is not included in the article's Creative Commons licence and your intended use is not permitted by statutory regulation or exceeds the permitted use, you will need to obtain permission directly from the copyright holder. To view a copy of this licence, visit http://creativecommons.org/licenses/by/4.0/. The Creative Commons Public Domain Dedication waiver (http://creativeco mmons.org/publicdomain/zero/1.0/) applies to the data made available in this article, unless otherwise stated in a credit line to the data. 
the diversity, complexity and rarity of these disorders and the lack of access to specialized diagnostic tools [2, 4-6]. A recent survey of patients with mitochondrial disorders, for example, showed that most of them consult five or more clinicians and received at least one incorrect diagnosis before the establishment of the final diagnosis [7]. In 2009, the Council of the European Union published recommendations addressed to the Member States in order to encourage them to improve the access of patients with rare diseases to high-quality diagnosis, care, treatment, social support and information $[2,8,9]$.

One of the deliverables of the Belgian action plan for rare diseases, published in December 2013, is to improve the patients' diagnosis and follow-up [10]. Because most of rare diseases have a genetic origin, the Belgian centers of human genetics were firstly involved in the process, followed by a specific action focused on biochemical laboratory tests performed by medical laboratories. Indeed, genetic and biochemical tests are highly complementary in order to investigate and follow rare diseases' mechanisms, the underlying biochemistry, cellular pathways and response to treatments [11].

A critical analysis of the Belgian situation in 2015 identified three factors limiting the patients' access to specialized biochemical laboratory tests: (1) lack of reimbursement for a number of specialized tests within the framework of the public health system, (2) absence of reference laboratories with scientific and technical expertise for complex tests, and (3) need for an official referral framework for outsourcing tests unavailable in Belgium to foreign laboratories.

To address these shortcomings, the Belgian Institute for Health (Sciensano) was mandated by the Belgian National Institute for Health and Disability Insurance (RIZIV-INAMI) to (1) review the reimbursement of biochemical tests prescribed in Belgium in the context of rare diseases, and (2) organize the selection, recognition and financing of Belgian reference laboratories (RLs) and foreign referral laboratories for selected biochemical tests. A task force was established by Sciensano with clinical pathologists and clinicians.

This paper describes the approach used to identify and prioritize the biochemical analyses that should be covered by the Belgium public health system, either through traditional reimbursement of clinical pathology tests or through the development of a new system of RLs and foreign referral laboratories, as well as RLs' selection procedure and duties.

\section{Materials and methods Data collection}

In May and June 2015, Sciensano performed a screening of the European expert centres and medical laboratories providing diagnostic tests used in the context of rare diseases published on Orphanet [12], and of peer-reviewed scientific publications describing the use and validation of biochemical tests used for rare diseases.

The inventoried analyses were classified based on their respective domains (clinical chemistry, endocrinology, haematology, coagulation and hemostasis, immunology and non-infectious serology, toxicology, therapeutic monitoring) and, when necessary, subclassified according to biological matrices (blood, plasma, serum, dry blood spots, urine, urinary stones, feces, cerebrospinal fluid, saliva, amniotic fluid) and/or chemical classes of metabolites/proteins (amino acids and derivates, pterins, organic acids, steroid acids, purines/ pyrimidines, sugars, lipids and acylcarnitines, porphyrins, vitamins, different proteins classes [e.g. transcobalamines, chemokines, iron-binding blood plasma glycoproteins, lectins, (apo-) lipoproteins, immunoglobulins, serum free light chains], cytoplasmic enzymes, lysosomal enzymes, mitochondrial enzymes, inhibitors [e.g. Alfa-1-antitrypsin], regulators [e.g. 14-3-3 proteins], complement control proteins [e.g. Factor $\mathrm{H}$ ], cofactors [e.g. molybdenum cofactor], and other metabolites and components [e.g. $\alpha$-aminoadipic semialdehyde, trimethylamine, sulfites, etc.]). Of note, one metabolite assessed in two different matrices, was inventoried as two different analyses.

Subsequently, a survey was sent in July 2015 to the Belgian laboratories of clinical pathology performing those analyses.

For each test, these laboratories had to provide the following information:

a. The annual number of tests performed;

b. The rare disease(s) for which the test is performed;

c. For analyses not performed in-house, the name of the external laboratory to which the analysis is outsourced and whether the laboratory wanted to develop it in-house by 2020;

d. The average turnaround time (TAT). The TAT was defined as the time between the reception of the sample by the laboratory and the moment the result is reported (in-house or by a foreign laboratory) [13].

The survey was accompanied by a cover letter specifying the context and objectives of the study, and ensuring that collected data would be stored and treated in complete confidentiality and anonymity. Participants had over two months to complete it and were free to add additional tests of clinical pathology if they were not yet included in the list. All answers were then collected and put together by Sciensano. 


\section{Analyses prioritization}

In November 2015, a "Rare Diseases Working Group (RDWG)", composed of clinical pathologists with a particular expertise in rare diseases and one Sciensano scientific moderator, was set-up by the Belgian Commission on Clinical Pathology.

Between December 2015 until June 2016, the RDWG met 2 to 5 times per month in order to discuss the usefulness, clinical relevance, limitations and costs of the analyses for which information was collected during the survey. The goal was to evaluate the feasibility of their financing and identify analyses which should be prioritized for reimbursement. Particular attention was paid to tests for which there was disagreement about the clinical utility. The goal was to sort out whether discrepancies of opinions were due to evidence-based disagreements over the use of the analysis in clinical practice or to differences in laboratories' functioning.

\section{Funding modalities}

The INAMI-RIZIV proposed three possible financing modalities: (a) nomenclature reimbursement codes, (b) recognition and financing of RLs, or (c) financing of the outsourcing of analyses unavailable in Belgium to foreign laboratories. At the request of Sciensano, the RDWG defined for each test the financing modality and the total the annual budget that should be allocated to each type of financing modality.

In August 2016, Sciensano submitted a proposal of priority analyses that should be funded and selection criteria for the Belgian RLs to the RIZIV-INAMI. The description of each analysis was accompanied by an annual budget estimate based on the analytical costs and type of financing modality proposed by the RDWG. The proposal of priority analyses and required annual budget was approved by the INAMI-RIZIV in December 2016.

\section{Implementation phase}

The approved proposal was implemented by Sciensano and the RDWG from January 2017 until August 2018. This consisted of (1) writing the nomenclature reimbursement codes (including reimbursement modalities) and publishing them in a Belgian royal decree (2) selecting the Belgian RLs, and (3) formalizing offcial collaborations with some foreign laboratories. The INAMI-RIZIV evaluated this proposal from October 2018 until December 2019.

\section{Statistical analyses}

One-way analysis of variance (ANOVA) was made with GraphPad Prism 8.2.0 (GraphPad Software, San Diego, CA).

\section{Results}

Figure 1 illustrates the study outline.

\section{Analyses inventory}

Unreimbursed analyses of clinical pathology used in the context of rare diseases were identified based on the literature search and survey that was sent to the $17 \mathrm{Bel}-$ gian laboratories of clinical pathology performing these analyses (8 university laboratories and 9 non-university laboratories).

\section{Survey results}

All laboratories completed the survey. When necessary, they added analyses that they perform and that were not included in the initial survey. The survey enabled Sciensano to identify 483 analyses of clinical pathology used in the context of rare diseases. Of these tests, 163 (34\%) were unreimbursed in July 2015 and, therefore covered by the Belgian public healthcare system. In this case, the patient's personal share varied between 0 and 20 euros per laboratory test request.

\section{Selection of priority analyses}

Among the unreimbursed analyses, the RDWG selected priority tests based on the survey answers and, more specifically, on (1) the lack of existing reimbursed tests in the Belgian nomenclature for a rare disorder, (2) the absence of existing proposals for reimbursement already submitted to the Belgian healthcare authorities, (3) the clinical utility of the test (showing higher medical and/or analytical benefits compared to other existing techniques; some obsolete tests were replaced as part of the exercise), (4) the high specificity of the analyses for rare diseases (analyses widely performed in other contexts than the diagnosis or follow-up of rare diseases patients, were not included in the list of priority analyses).

Using those criteria, 73 priority analyses were selected for coverage in the following fields: clinical chemistry (46), coagulation and hemostasis (11), immuno-haematology and non-infectious serology (9), hormonology (4), and haematology (3) (cf. Fig. 2). Among them, 64 analyses were performed in Belgium and 9 outsourced abroad. Moreover, 62 of the 64 analyses performed in Belgium (97\%) were only performed 


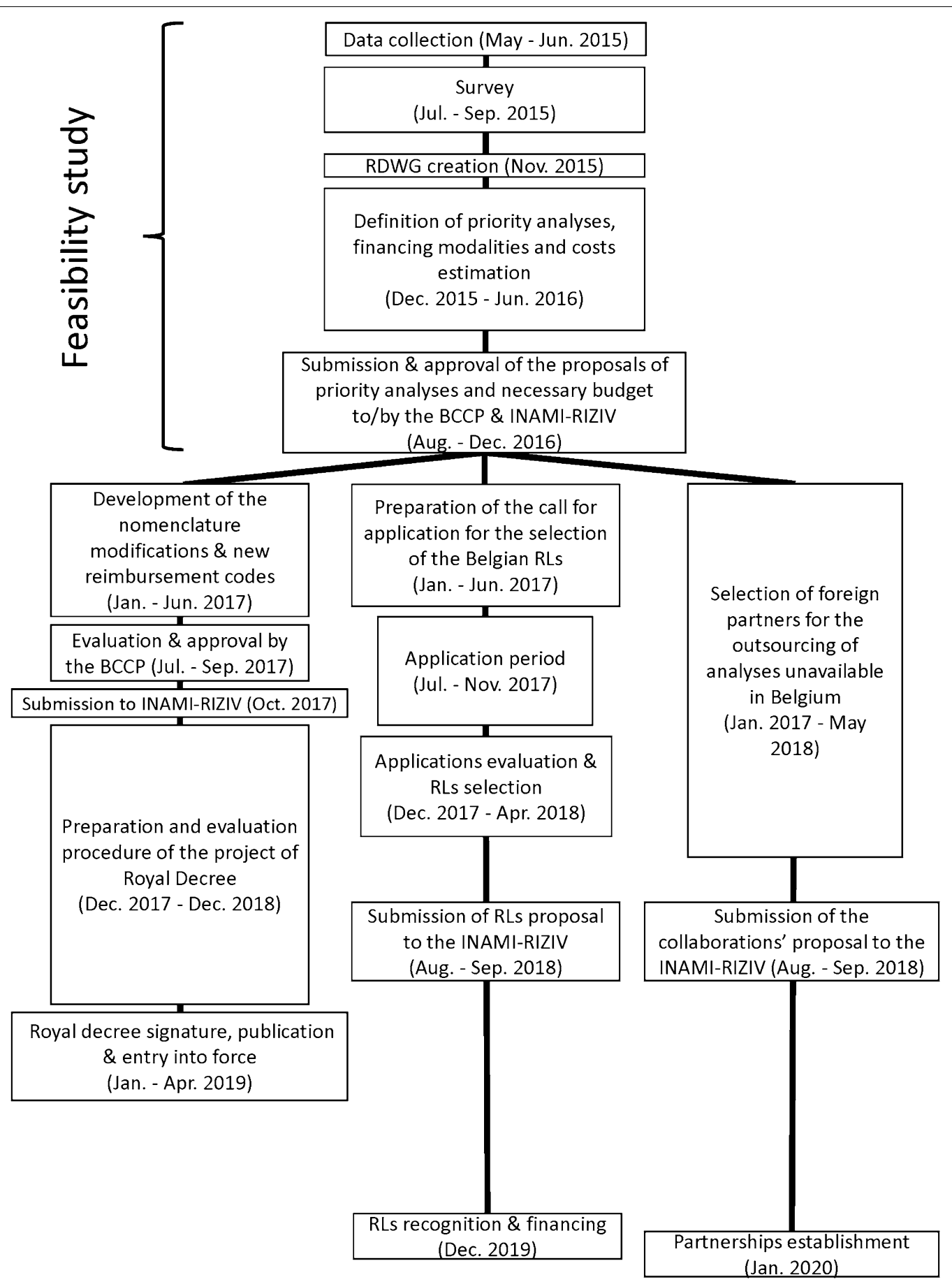

Fig. 1 Illustration of the different steps of the study. BCCP Belgian Commission on Clinical Pathology, INAMI-RIZIV National Institute for Health and Disability Insurance, RD Royal Decree, RDWG Rare Diseases Working Group, RLs Reference laboratories

in university hospital laboratories. A great disparity was observed among the annual volumes (from 1 to more than 5000 tests per year), as well as TAT (ranging from $40 \mathrm{~h}$ up to 2 months).

\section{Definition of financing modalities}

Table 1 summarizes the characteristics of the three types of financing modalities.

For analyses performed in Belgium, the choice of developing a reimbursement nomenclature code versus 


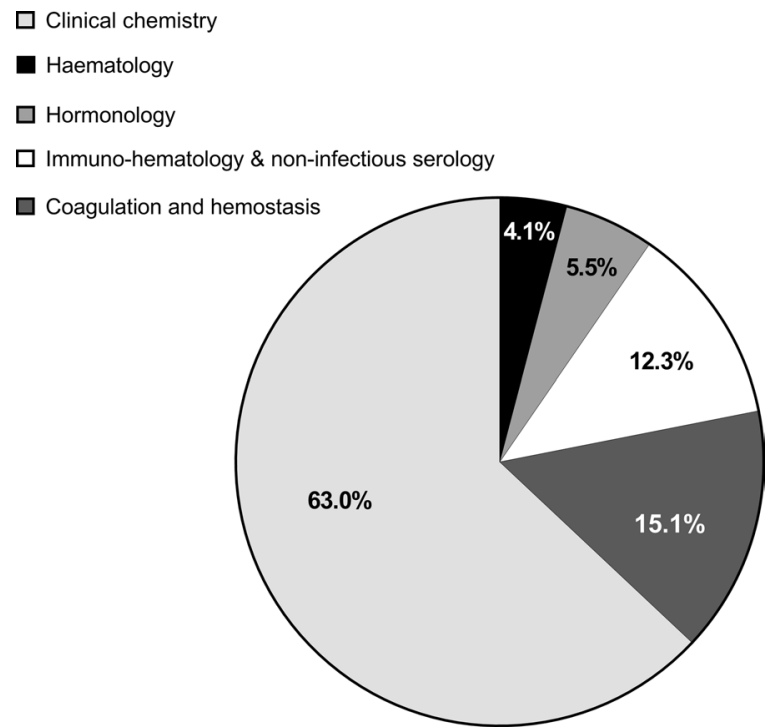

Fig. 2 Repartition of the selected financeable priority analyses among their respective domains of clinical pathology

selecting a Belgian reference laboratory (RL) was based on the degree of centralization of the performance of the test (performed by a limited versus larger number of laboratories) and the required level of medico-scientific expertise and/or specialized infrastructure.

The development of nomenclature codes or modification of existing codes was favored for analyses performed by at least 3 Belgian laboratories for clinical pathology. The selection of RLs on the other hand was preferred for analyses characterized by a low annual volume, requiring specific infrastructure and/or scientific expertise, and performed by 1 to 3 Belgian laboratories (cf. Fig. 3a, b). Finally, the development of formal collaborations with foreign laboratories was proposed to cover analytical and shipment costs for low volume analyses unavailable in Belgium and thereby outsourced abroad.

\section{Development of reimbursement nomenclature codes}

The Belgian reimbursement system for laboratory tests combines a fee for service per test and a flat rate which varies in function of the tests requested. The INAMIRIZIV is responsible for establishing the flat rates, reimbursement fee per test and reimbursement rules for test (e.g. maximum one per year, only reimbursed in patients with a specific disorder, etc.), as well as for organizing, managing and supervising its correct application [14-16].

A reimbursement code for a clinical pathology test contains the (1) name of the test including possible additional technical requirements, (2) domain of clinical pathology to which the test belongs, (3) biological matrix, (4) theoretical reimbursement tariff represented by a 'B-value', (5) maximal frequency of reimbursement (e.g. maximum 1 test/day) and, if applicable, (6) diagnostic and/or cumulation rules. Of note, the theoretical tariff is calculated by multiplying the analysis' B-value by the B-coefficient which is regularly adapted by the INAMI-RIZIV (current

Table 1 Financing modalities characteristics

\begin{tabular}{|c|c|c|c|}
\hline Financing modalities & $\begin{array}{l}\text { Nomenclature reimbursment } \\
\text { codes }\end{array}$ & Reference laboratories (RLs) & $\begin{array}{l}\text { Conventions with foreign } \\
\text { laboratories }\end{array}$ \\
\hline Type of medical analyses & \multicolumn{3}{|l|}{ Analyses of clinical pathology } \\
\hline Analyses'availability & \multicolumn{2}{|l|}{ Available in Belgium } & Not available in Belgium \\
\hline Annual volume & High & Moderate to low & Low \\
\hline $\begin{array}{l}\text { Laboratories who can benefit from } \\
\text { the financing }\end{array}$ & $\begin{array}{l}\text { All Belgian laboratories of clinical } \\
\text { pathology }\end{array}$ & $\begin{array}{l}\text { Only Belgian laboratories of } \\
\text { clinical pathology recognized } \\
\text { as RLs }\end{array}$ & $\begin{array}{l}\text { Specific foreign laboratories of clinical } \\
\text { pathology }\end{array}$ \\
\hline Laboratories'selection procedure & None & $\begin{array}{l}\text { Belgian call for application } \\
\text { By Sciensano } \\
\text { Every } 5 \text { years }\end{array}$ & $\begin{array}{l}\text { By the RDWG of the BCCP and } \\
\text { Sciensano } \\
\text { Every year }\end{array}$ \\
\hline Components of the financing & Performance of the analysis & $\begin{array}{l}\text { Analytical costs } \\
\text { Accreditation } \\
\text { Quality controls } \\
\text { Specific administrative costs }\end{array}$ & $\begin{array}{l}\text { Analytical costs } \\
\text { Shipment costs }\end{array}$ \\
\hline Financing source & \multicolumn{3}{|c|}{$\begin{array}{l}\text { INAMI-RIZIV (through a budget envelop specifically dedicated to the Action } 1 \text { of the Belgian plan for rare } \\
\text { diseases) }\end{array}$} \\
\hline $\begin{array}{l}\text { Follow-up of laboratories' activities } \\
\text { and quality of the analyses }\end{array}$ & \multicolumn{3}{|c|}{ By the RDWG of the BCCP and Sciensano } \\
\hline $\begin{array}{l}\text { Annual evaluation of the necessary } \\
\text { budget }\end{array}$ & \multicolumn{3}{|c|}{ By Sciensano and the INAMI-RIZIV Insurance Committee } \\
\hline
\end{tabular}



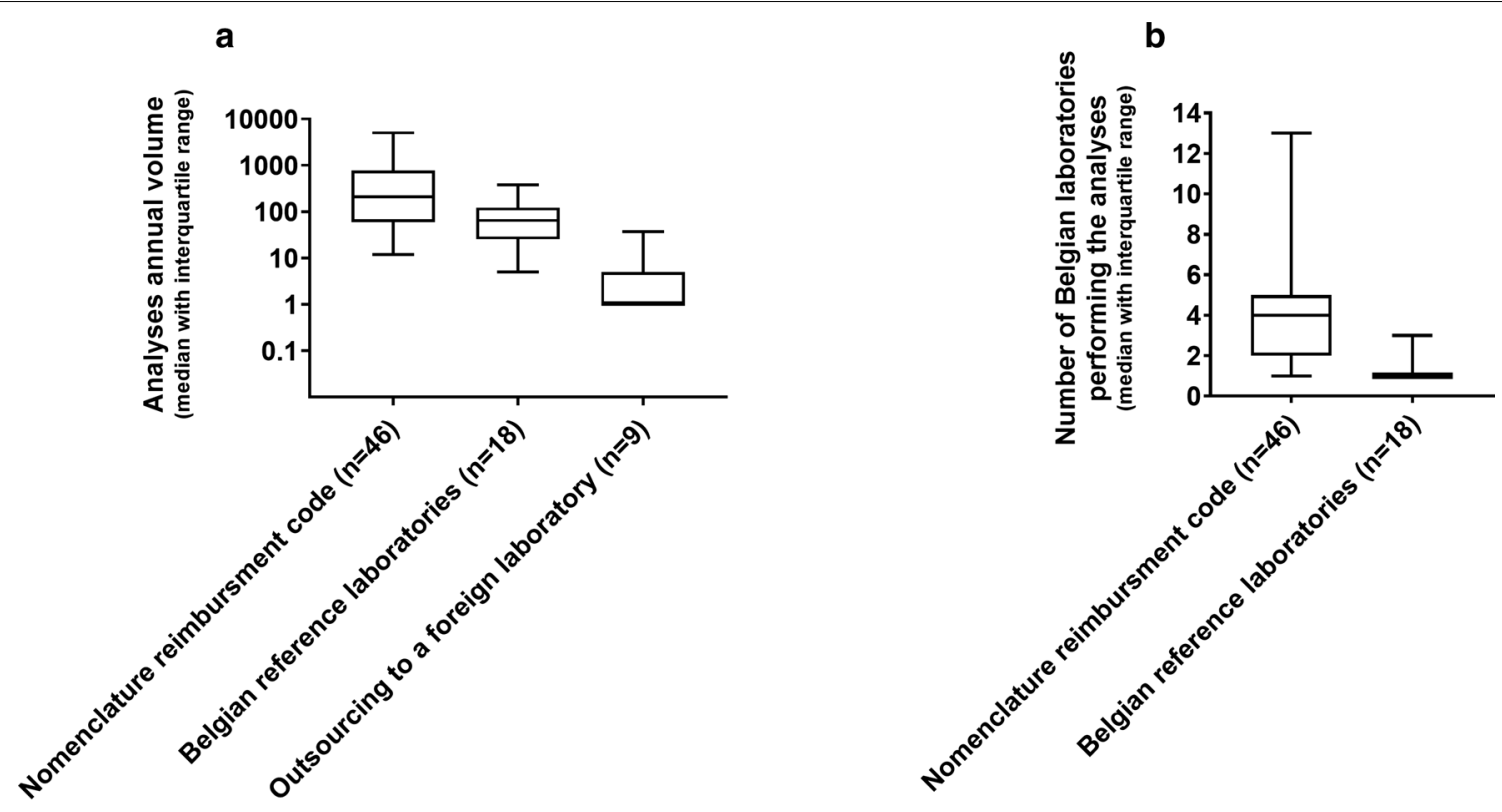

FINANCING MODALITIES

Fig. 3 Volumes reported in 2016 for the 73 priority analyses categorized according to their financing modality

value: $B=0032012$ since $01 / 01 / 2020$ [17]). For instance, a B-value of 1000 corresponds to a theoretical tariff of approximately $32 €$ (including reagents/materials, personnel, quality controls costs). The fee of service and flat rate are calculated based on the theoretical tariffs of the requested tests.

Diagnostic rules give an accurate description of the context in which the test can be reimbursed (e.g. specific patient population, clinical symptoms) while cumulation rules define which tests cannot be combined for reimbursement.

The costs of the medical services (including medical laboratory analyses) that are not included in the Belgian reimbursement system are invoiced to the patients. By contrast, $25 \%$ of the costs of medical services with a nomenclature code are reimbursed by the INAMI-RIZIV. The rest is mainly charged to the health insurance of the patient. In some cases (not applicable to patients with chronic diseases), the patient pays a small amount that represents the difference between the cost of the medical service and the interventions of the INAMI-RIZIV and health insurance.

Between March and July 2016, the RDWG proposed nomenclature codes for all the priority tests selected for a reimbursement. Based on the B-values and number of tests performed reported in the survey, the total annual budget was calculated and submitted in August 2016 to the INAMI-RIZIV. After the budget approval, diagnostic and cumulation rules were developed by the RDWG between January and June 2017. The proposal for new reimbursement codes was approved by the Belgian Commission on Clinical Pathology in September 2017 and submitted to the INAMI-RIZIV in October 2017. After evaluation and approval by different INAMI-RIZIV and external bodies (i.e. Technical Medical Council, Insurance Committee, national medical-mutualistic commission), a royal decree project was prepared and submitted to the Belgian Budget ministry and Healthcare and Social Affairs ministry. The royal decree formalizing the modification of 4 existing nomenclature reimbursement codes and the creation of 42 new codes was published on 3 February 2019 and came into effect on 1 April 2019 [18]. Table 2 contains the list of the 42 new nomenclature codes.

\section{Selection of the reference laboratories (RLs)}

The selection criteria for the Belgian RLs are summarized in Table 3. Special attention was paid to the laboratories' quality management system, its medico-scientific expertise (including the extent of its collaborations with external rare diseases experts), the education program addressed to the laboratory staff and medical prescribers, and whether the laboratory will be able to offer the test during at least 5 years.

The call for application was prepared by Sciensano between January and June 2017 and included: 
Table 2 List of the 42 new reimbursement nomenclature codes [18]

\begin{tabular}{|c|c|c|}
\hline Domains of clinical pathology & Biological matrices & Names of the nomenclature codes \\
\hline \multirow[t]{19}{*}{ Clinical chemistry } & \multirow[t]{9}{*}{ Blood } & $\begin{array}{l}\text { Separated identification and assessment of C22-C26 fatty acids, phytanic acid and pristanic } \\
\text { acid by mass spectrometry }\end{array}$ \\
\hline & & Methylmalonic acid and succinylacetone assessment \\
\hline & & Pipecolic acid assessment \\
\hline & & Guanidinoacetate and creatine assessment \\
\hline & & Measurement of alpha-D-galactose 1-phosphate (Gal-1-P) in erythrocytes \\
\hline & & Separated assessment of cholestanol, 7-dehydrocholesterol and 8-dehydrocholesterol \\
\hline & & $\begin{array}{l}\text { Separated assessment of desmosterol, lathosterol, campesterol, sitosterol and 27-hydroxycho- } \\
\text { lesterol }\end{array}$ \\
\hline & & Identification of asialotransferrin, monosialotransferrin, and asialotransferrin \\
\hline & & Determination of the Alpha-1-proteinase inhibitor (=alpha-1-antitrypsin) phenotype \\
\hline & Serum/plasma & Organic acids assessment \\
\hline & \multirow[t]{4}{*}{ Urine } & Guanidinoacetate and creatine assessment \\
\hline & & Separated assessment of polyols after fractionation \\
\hline & & Separated assessment of mono- and disaccharides after fractionation \\
\hline & & Separated assessment of polyols, monosaccharides and disaccharides after fractionation \\
\hline & \multirow[t]{3}{*}{ Cerebrospinal fluid } & Specific mass spectrometric identification and dosage of organic acids \\
\hline & & Specific assessment of amino acids by LC-MS/MS after derivatization and fractionation \\
\hline & & Guanidinoacetate and creatine assessment \\
\hline & Stool & Measurement of pancreatic Elastase 1 \\
\hline & Amniotic fluid & Separated assessment of 7-dehydrocholesterol and 8-dehydrocholesterol \\
\hline \multirow[t]{5}{*}{ Hormonology } & \multirow[t]{4}{*}{ Blood } & Assessment of fibroblast growth factor 23 \\
\hline & & Assessment of pregnenolone \\
\hline & & Assessment of 17-hydroxypregnenolone \\
\hline & & Proinsulin measurement \\
\hline & Saliva & Cortisol measurement \\
\hline Haematology & Blood & Eosin-5'-maleimide (EMA) binding test \\
\hline \multirow[t]{11}{*}{ Coagulation and hemostasis } & \multirow[t]{11}{*}{ Plasma } & Alpha 2-Antiplasmin measurement \\
\hline & & Functional analysis of von Willebrand factor-cleaving protease (ADAMTS13) \\
\hline & & Identification of the von Willebrand factor-cleaving protease inhibitor \\
\hline & & Diagnosis of type $2 \mathrm{~N}$ von Willebrand disease \\
\hline & & von Willebrand factor collagen-binding activity assay \\
\hline & & von Willebrand factor multimer analysis \\
\hline & & von Willebrand factor propeptide assay \\
\hline & & $\begin{array}{l}\text { Detection of heparin-induced antibodies (= diagnosis of heparin induced thrombocytopenia } \\
{[\mathrm{HIT]})}\end{array}$ \\
\hline & & Functional analysis of HIT antibodies \\
\hline & & Platelet secretion assay \\
\hline & & $\begin{array}{l}\text { Measurement of prekallikrein (Fletcher Factor) anticoagulant activity and of high-molecular- } \\
\text { weight kininogen }\end{array}$ \\
\hline \multirow[t]{5}{*}{$\begin{array}{l}\text { Immuno-haematology and non- } \\
\text { infectious serology }\end{array}$} & \multirow[t]{5}{*}{ Serum } & $\begin{array}{l}\text { Detection of anti-podocytes antibodies in the context of membranous glomerulonephritis } \\
\text { diagnosis }\end{array}$ \\
\hline & & $\begin{array}{l}\text { Detection of anti-podocytes antibodies in the context of membranous glomerulonephritis } \\
\text { follow-up }\end{array}$ \\
\hline & & Determination of anti-acetylcholine receptor antibodies \\
\hline & & $\begin{array}{l}\text { Immunoassay identification of autoantibodies against bullous pemphigoid (BP) antigen 180, } \\
\text { BP230 (bullous pemphigoid antigen 1), DSG1 (desmoglein 1), DSG3 (desmoglein 3), type VII } \\
\text { collagen and envoplakin }\end{array}$ \\
\hline & & $\begin{array}{l}\text { Follow-up of the production of autoantibodies against bullous pemphigoid (BP) antigen 180, } \\
\text { BP230 (bullous pemphigoid antigen 1), DSG1 (desmoglein 1), DSG3 (desmoglein 3), type VII } \\
\text { collagen and envoplakin by immunoassay }\end{array}$ \\
\hline
\end{tabular}


Table 3 Illegibility criteria for the selection of the Belgian Reference laboratories

\section{Main aspects}

Localisation, structure, organization and governance

Quality

Reporting of analytical results and communication skills
Criteria to be met

Applicants are laboratories of clinical pathology located in Belgium and certified according to the Royal Decree of 3 December 1999 [19]

Applicants provide the full contact details of the laboratory, its director, quality coordinator and of the clinical pathologist(s) responsible for the performance of the analysis for which they apply Applications in the form of a consortium have to be justified

A clear description of the tasks performed by each laboratory composing the consortium must be provided

Applicants have to join the following documents to the application file:

Full content of the laboratory quality manual

Description of the method and equipment used to perform the analysis (Standard Operating Procedure)

Analysis validation file (including the reference values and bibliographic references used to validate the method and interpret analytical results)

Description of the External Quality Assessment programs and/or ring tests related to the analysis for which they apply and to which they participate

Copy of the laboratory accreditation certificate according to the norm ISO15189 [20]

Applicants have to specify:

The units used to report the results and if those units are SI units or not (if not, they also have to mention the reason)

Their mean turnaround time (TAT) ${ }^{a}$ for the analysis for which they apply (expressed in days, with a standard deviation if desired)

The link to their website where the prescribers can find the analytical TAT

If they undertake to respect the TAT mentioned on their website/ prescription forms

If they undertake to be more flexible and reduce their TAT for urgent analyzes in order to guarantee the good management of the patient

If they are able to report the results in at least one of the Belgian national languages and in English

If they accept to publish the prescription forms in French, Dutch and English on their website

If they accept that information related to their activities (no patients details/personal information) will be used to update and enrich the Belgian rare diseases registries
Evaluation procedure

Documentation audit On-site visits for RL in the form of a

consortium

Documentation audit On-site visits

Documentation audit 
Table 3 (continued)

\begin{tabular}{|c|c|c|}
\hline Main aspects & Criteria to be met & Evaluation procedure \\
\hline Scientific and medical expertise & $\begin{array}{l}\text { Applicants have to provide: } \\
\text { Their annual volume of tests during the } 5 \text { last years for the analysis } \\
\text { for which they apply } \\
\text { Their list of scientific communications (peer-reviewed publications, } \\
\text { posters, etc.) related to rare diseases management } \\
\text { A short description of their projects in the domain of clinical pathol- } \\
\text { ogy to which the analysis for whom they apply belongs (basic } \\
\text { research projects, clinical research, epidemiological research, } \\
\text { validation of new methods, acquisition of new equipment, etc.) } \\
\text { Their affiliations to international (reference) networks with a short } \\
\text { description of the (1) network spectrum of activities, (2) applicants } \\
\text { duties/activities within the network, and (iii) frequency of appli- } \\
\text { cants' meetings/exchanges of information with other network } \\
\text { members } \\
\text { The names of the databases in which analytical results are recorded } \\
\text { (patient's medical record, laboratory database, Regional/national } \\
\text { database, network database, etc.) } \\
\text { A description of their participation to multidisciplinary meetings } \\
\text { (frequency, medical disciplines [specializations] of the experts who } \\
\text { attended the meetings, aspects discussed during the meetings } \\
\text { [clinical cases, analytical results interpretation, communication } \\
\text { between the laboratory and prescribers, development of guide- } \\
\text { lines/healthcare algorithms, etc.]) } \\
\text { A description of the diagnosis and/or follow-up guidelines/algo- } \\
\text { rithms that they may develop for some rare diseases } \\
\text { A description of the training programs that they develop and of the } \\
\text { targeted audience }\end{array}$ & Documentation audit \\
\hline Activities sustainaibility & $\begin{array}{l}\text { Candidates undertake to carry out the analysis for which they apply } \\
\text { for at least } 5 \text { years in the case of a recognition as } R L \text { and confirm } \\
\text { that they possess the necessary qualified personnel, equipment } \\
\text { and infrastructure to carry out the analysis during this period of } \\
\text { time }\end{array}$ & Documentation audit \\
\hline
\end{tabular}

$R L$ reference laboratory, SI International System of Units, TATTurnaround Time

a For analyses made in Belgium, the TAT corresponds to the time period between the reception of the sample by the laboratory and the moment at which the clinician receives the validated results; for analyses outsourced abroad, it corresponds to the time period between the test prescription and the moment at which this clinician receives the validated results

1. an introductory letter explaining the call's context and objectives;

2. an explanatory document describing the applicants' profile, RLs missions, application documents, selection procedure, and analyses for which applicants could apply for a recognition of expertise;

3. the application documents that must be completed in English (application form and agreement forms for the submission of the application signed by the laboratory director and clinical pathologist responsible for the performance of the test);

4. French and Dutch translations of the application documents provided to ensure an optimal comprehension of the application documents written in English.

The call for application was officially opened on 1 July 2017. The laboratories had five months to apply for one or several analyses. Moreover, the laboratories were free to apply together in the form of a consortium. In this case, the relevance of the consortium had to be justified in the application form.

The evaluation procedure took place between December 2017 and April 2018. All applications were reviewed by three independent experts (not linked to the Belgian laboratories of clinical pathology). This was performed through documentation audits of the application form, laboratory quality manual, accreditation certificate, validation file and standard operating procedure (SOP) for the performance of the analysis, peer-reviewed publications illustrating the laboratory scientific expertise and collaborations, guidelines, decision algorithms for the diagnosis/follow-up of rare diseases or education material developed by the laboratory). If necessary, additional on-sites visits were performed in March and April 2018 by Sciensano in order to assess practical aspects of the analysis' validation and SOP. 


\begin{tabular}{|c|c|c|}
\hline Institutions & Belgian Reference Laboratories (RLs) & Main clinical indications \\
\hline \multirow{2}{*}{ A } & Analysis of plasmalogens in red blood cells & $\begin{array}{l}\text { Peroxisomal disease and specific plasmalogens biosynthesis } \\
\text { defects (e.g. RCDP, Refsum disease, Zellweger disease) }\end{array}$ \\
\hline & Cytogenetic radiosensitivity assay & $\begin{array}{l}\text { Ataxia telangiectasia, Nijmegen breakage syndrome, Fanconi } \\
\text { anemia, SCID, Bloom syndrome }\end{array}$ \\
\hline \multirow{2}{*}{$\mathrm{B}, \mathrm{C}$} & Spectrofluorimetric assessment of plasma porphyrins & \multirow{4}{*}{ Porphyria } \\
\hline & Assessment of free erythrocyte protoporphyrins (FEP-test) & \\
\hline \multirow{7}{*}{ B } & Assessment of plasma porphobilinogen & \\
\hline & Fractionation of plasma porphyrins (confirmation test) & \\
\hline & $\begin{array}{l}\text { Analysis of the erythrocytes deformability using ektacytometry } \\
\& \text { separation of red blood cells membrane proteins by SDS-PAGE }\end{array}$ & $\begin{array}{l}\text { Hereditary spherocytosis, rare constitutional hemolytic anemia } \\
\text { due to a red cell membrane anomaly }\end{array}$ \\
\hline & Immunological assessment of complement component Factor B & \multirow{4}{*}{$\begin{array}{l}\text { Atypical hemolytic-uremic syndromes, (autoimmune or } \\
\text { constitutional) hemolytic anemias, immunodeficiency due to a } \\
\text { complement cascade component deficiency }\end{array}$} \\
\hline & Immunological assessment of complement component Factor Bb & \\
\hline & Immunological assessment of complement component Factor D & \\
\hline & Immunological assessment of complement component Factor $\mathrm{P}$ & \\
\hline \multirow[b]{2}{*}{ D } & Assessment of intra-leukocyte cystine & Cystinosis \\
\hline & Determination of 5-methyltetrahydrofolate in CSF & $\begin{array}{l}\text { Cerebral folate deficiency, AADC deficiency, DHPR deficiency, } \\
\text { neurodegenerative syndrome due to FOLR1 deficiency, } \\
\text { constitutional megaloblastic anemia with severe neurologic } \\
\text { disease (DHFR deficiency), homocystinuria due to MTHFR } \\
\text { deficiency, neurometabolic disorder due to serine deficiency, } \\
\text { mitochondrial diseases (e.g. Kearns-Sayre syndrome) }\end{array}$ \\
\hline E & Quantification of $\mathrm{B} 6$ vitamers in plasma (PLP, PL,PM,PN,PA) & $\begin{array}{l}\text { Pyridoxine-dependent epilepsy, refractory neonatal seizures, } \\
\text { hypophosphatasia, homocystinuria, primary hyperoxaluria, } \\
\text { follow-up of pyridoxine and isoniazid therapies in patients with } \\
\text { tuberculosis, isoniazid toxicity }\end{array}$ \\
\hline $\begin{array}{l}\text { a: Consortium between } \\
\mathbf{D}^{\alpha} \underline{\text { and }} \mathrm{F}^{\boldsymbol{\beta}}\end{array}$ & $\begin{array}{l}\text { Assessments of } \delta 1 \text {-piperideine-6-carboxylate }(\mathrm{P} 6 \mathrm{C}) \text { in plasma }{ }^{\alpha} \text { and } \\
\mathrm{P} 6 \mathrm{C} \& \alpha \text {-aminoadipic semialdehyde ( } \alpha \text {-AASA) in urine }{ }^{\beta}\end{array}$ & $\begin{array}{l}\text { Pyridoxine-dependent epilepsy, encephalopathy due to sulfite } \\
\text { oxidase deficiency, sulfite oxidase deficiency due to } \\
\text { molybdenum cofactor deficiencies }\end{array}$ \\
\hline $\begin{array}{l}\text { b: Consortium between } \\
\mathrm{A}^{\mathrm{V}} \text { and } \mathrm{E}^{\mathrm{\delta}}\end{array}$ & $\begin{array}{l}\text { Assessment of pterins in urine }{ }^{\gamma} \text { and of DHPR activity in dry blood } \\
\text { spots }^{\bar{\gamma}}\end{array}$ & $\begin{array}{l}\text { Hyperphenylalaninemia due to } \mathrm{BH} 4 \text { deficiency, DHPR } \\
\text { deficiency }\end{array}$ \\
\hline \multicolumn{3}{|c|}{ A: Department of Laboratory Medicine, UZ Gent, Gent } \\
\hline \multicolumn{3}{|c|}{$\begin{array}{l}\text { B: Laboratoire Hospitalier Universitaire de Bruxelles - } \\
\text { Universitair Laboratorium Brussel (LHUB-ULB), Brussels }\end{array}$} \\
\hline \multicolumn{3}{|c|}{ C: Department of Laboratory Medicine, UZ Leuven, Leuven } \\
\hline \multicolumn{3}{|c|}{$\begin{array}{l}\text { D: Department of Laboratory Medicine, Cliniques universitaires } \\
\text { St Luc, Brussels }\end{array}$} \\
\hline \multicolumn{3}{|c|}{ E: Unilab Lg, CHU de Liège, Liège } \\
\hline \multicolumn{3}{|c|}{ F: Department of Clinical Chemistry, UZ Antwerpen, Edegem } \\
\hline
\end{tabular}

Fig. 4 Representation of the new Belgian reference laboratories. AADC aromatic L-amino acid decarboxylase, $B H 4$ tetrahydrobiopterin, CSF cerebrospinal fluid, DHFR dihydrofolate reductase, DHPR dihydropteridine reductase, FOLR1 folate receptor 1, MTHFR methylene tetrahydrofolate reductase, $P A$ pyridoxic acid, $P L$ pyridoxal, $P L P$ pyridoxal-phosphate, $P M$ pyridoxamine, $P N$ pyridoxine, $R C D P$ rhizomelic chondrodysplasia punctate, SCID severe combined immunodeficiency, SDS-PAGE sodium dodecyl sulfate polyacrylamide gel electrophoresis 


\section{Reference laboratories recognition}

Among the 18 analyses included in the call for application scope, RLs were recognized on 3 December 2019 for 16 analyses. The names of the institutions to which RLs belong, the names of the analyses for which they have been recognized and the main clinical indications of these tests, as well as RLs localization are illustrated in Fig. 4. All of them were Belgian university hospital laboratories which participate to External Quality Assessment schemes [EQAs] for 6 of the 16 analyses considered, international ring tests for 9 analyses, and a combination of both for 1 analysis). No applications were submitted for two analyses included in the call: assessment of the acid-labile subunit in serum and detection of the 14-3-3 protein in the cerebrospinal fluid.

RLs were set up in the form of a consortium of two laboratories for two analyses, namely for (1) the assessment of $\alpha$-aminoadipic semialdehyde in urine and $\delta 1$-piperideine-6-carboxylate in plasma and urine (mainly used in the case of pyridoxinedependent seizures), and (2) the assessment of pterins in urine and of the 6,7-dihydropteridine reductase activity in dry blood spots (used in the context of hyperphenylalaninemia).

For two other analyses (spectrofluorimetric assessment of plasma porphyrins and assessment of free erythrocyte protoporphyrins), two RLs have been recognized instead of one because of their similar quality, annual volume and long-term expertise recognized at the international level (membership to the European Porphyria Network for more than 10 years).

Prescription forms and criteria, as well as instructions for the sampling, storage and transport of the samples, have been developed for each RL.

The call for application for the Belgian RLs should be renewed every 5 years in order to allow modifications of the Belgian RLs scope based on adaptations of the activities of the Belgian laboratories of clinical pathology and tests' availability in Belgium.

\section{Collaborations with foreign laboratories}

After the evaluation of the quality, expertise and costs of different European laboratories performing the priority analyses that are unavailable in Belgium, partnerships have been developed with 5 foreign partners for the outsourcing of 9 analyses (cf. Fig. 5). The efficiency, and quality of analyses outsourced abroad, as well as the needs of collaborations' renewal based on the evolution of the tests availability in Belgium, will be annually reviewed by the RDWG.

\section{Impact of the project on the management of the patients} with rare diseases

The implementation of new reimbursement conditions for a large number of analyses has improved the patients' access to specialized diagnostic tests. Indeed, these analyses were previously performed for free by the Belgian medical laboratories or charged to the patients. Since the entry into force of the 42 new reimbursement codes, the laboratories are paid for the performance of these tests and the costs are no longer charged to the patients. Thus, between 1 April and 31 December, 2019, 8.599 tests could be reimbursed under the 42 new nomenclature codes. This represents a saving of $€ 282.029,84$ for the patients with rare diseases and Belgian medical laboratories in a nine-months period. The related expenditures of the INAMI-RIZIV had amounted to $€ 70.507,46$ (average: $€ 7834,16$ per month). The remainder $(€ 211.522,38)$ had been charged to the health insurances of the patients.

Besides, the selection of RLs has mainly helped to improve the management of the patients with rare diseases by increasing the availability of some highly-specialized tests in Belgium and by establishing a control and follow-up framework for the RLs activities. In that respect, some analyses that were not available in Belgium before this study (i.e. the assessments of the dihydropteridine reductase activity in dried blood spots, B6 vitamers in plasma, pterins in urine, $\alpha$-aminoadipic semialdehyde and 81 -piperideine-6-carboxylate in urine) have been developed by some Belgian university laboratories of clinical pathology after the presentation of the results of the feasibility study in 2016.

Concerning the quality of the tests, this project also enabled to rationalize the outsourcing and performance of rare analyses. Before 2016, some medical analyses covered by this project were heterogeneously outsourced to several Belgian or foreign laboratories, even if available in Belgium. This happened without any harmonization of the outsourcing procedure or possible control and follow-up of the volumes, quality, TAT, or costs of the tests by the Belgian healthcare authorities. In that respect, the recognition of Belgian RLs in 2019 enabled to centralize the performance of some analyses within one Belgian RL versus 5 (assessment of pterins in urine), 3 (assessment of 5-methyltetrahydrofolate in cerebrospinal fluid) or 2 (assessments of plasmalogen levels in erythrocytes, and $\alpha$-aminoadipic semialdehyde and $\delta 1$-piperideine6-carboxylate in urine) different medical laboratories in 2015. This has had a positive impact on patients' management through the possible reduction of the TAT, and a better tracing of the samples and follow-up of the quality of the analyses.

Finally, the project also helped to reduce patients' costs for analyses that are not available in Belgium. Since 1 


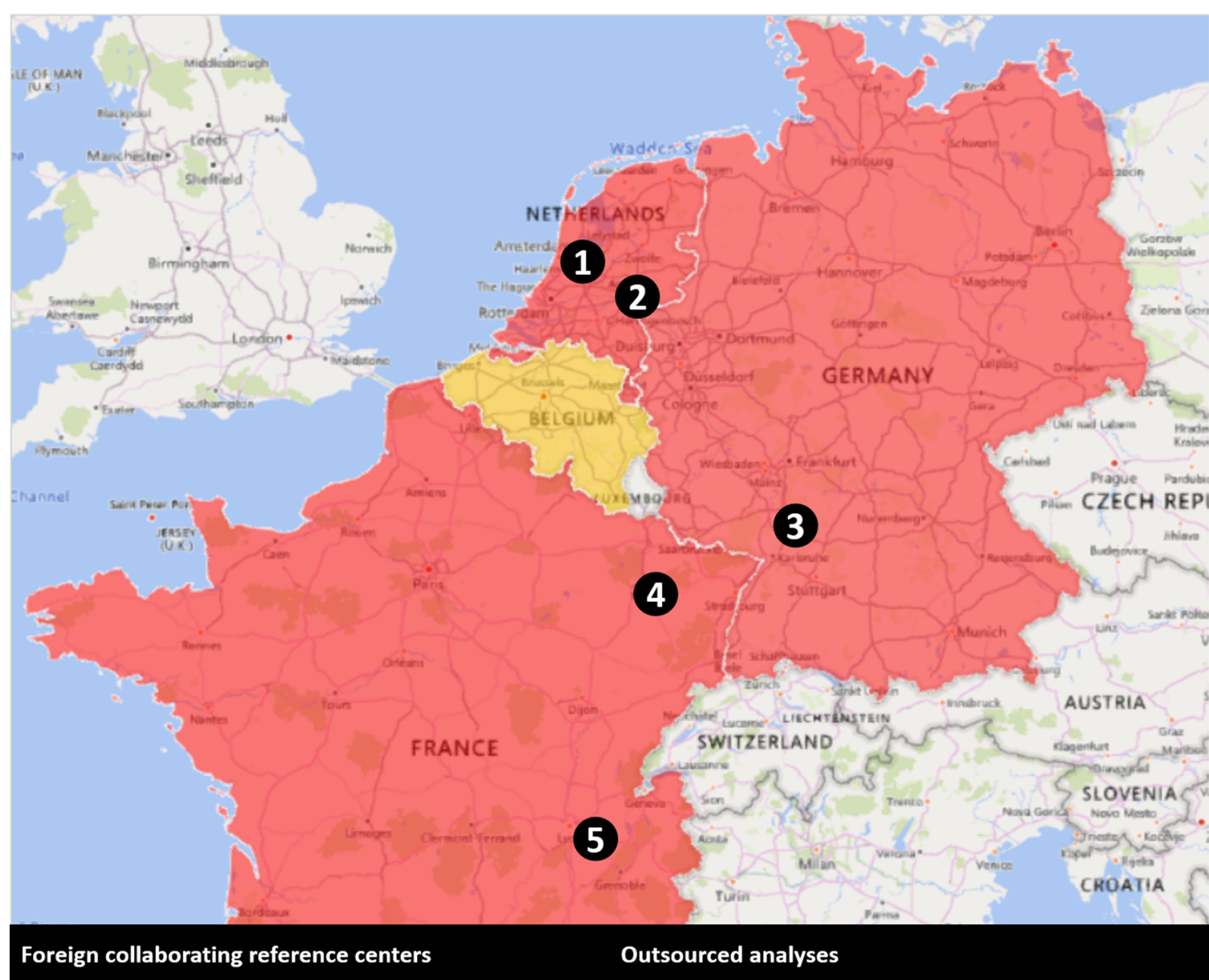

1 : Laboratory Genetic Metabolic Diseases Academic Medical Center

Amsterdam, The Netherlands

2 : Department of Laboratory Medicine, Radboud University Medical Center, Nijmegen, The Netherlands

3 : Metabolic laboratory, Center for Metabolic Diseases University Children's Hospital Heidelberg, Germany

4 : Biochemistry and Molecular Biology Laboratory CHU de Nancy - Hôpitaux de Brabois Vandoeuvre-lès-Nancy, France

5 : Department of Inborn Errors of Metabolism and Neonatal Screening Center of Biology and Pathology Est - CHU Lyon, Bron, France
- Measurement of urinary D- and L-2 hydroxyglutarate enantiomers

- Determination of S-Adenosylmethionine and SAdenosylhomocysteine in plasma and CSF

- Apolipoprotein C-III glycoforms in plasma by capillary zone electrophoresis

- Trimethylamine assessment in urine

- Pterins assessment in plasma

- Pterins assessment in CSF

- Biogenic amines assessment in CSF (Serotonin [5hydroxytryptamine; 5-HT], 5-hydroxyindoleacetic acid [5-HIAA], homovanillic acid [HVA], dopamine [3,4-dihydroxyphenethylamine; DA], 3-Omethyldopa [3-OMD], 5-hydroxytryptophan [5-HTP])

- Transcobalamins assessment in serum

- Diagnosis of molybdenum cofactor (MOCO) deficiency (measurement of sulfite oxidase activity in fibroblasts; analysis of genes MOCS1 and MOCS2)

Fig. 5 Foreign laboratories with whom collaborations were established for the outsourcing of analyses unavailable in Belgium. CSF cerebrospinal fluid 
January 2019, the shipment and analytical costs of the outsourced analyses are reimbursed through a specific financial envelop allocated by the INAMI-RIZIV.

Impact of the project on the Belgian RLs' cost-effectiveness This project also had a positive impact on the Belgian RLs cost-effectiveness. Indeed, before the official RLs recognition on 3 December 2019, the costs of the medical analyses performed by these laboratories were not or only partially invoiced to the patients. This situation induced insufficient incomes for the laboratories that performed these tests. The RLs recognition and funding by the Belgian healthcare authorities helped to deal with this problem. The RLs are receiving a reimbursement for the analyses performed since the 1 January 2019. Moreover, since 2019, RLs' costs related to their annual participation to quality controls and accreditation of the analyses for which they have been recognized are totally reimbursed. This is achieved through a specific annual envelop ( $€ 135.000$ in 2019 and 2020$)$ allocated by the INAMI-RIZIV.

The proposal of centralization of some analyses within one Belgian RL formulated after the feasibility study (2016) also helped to increase the Belgian laboratories' annual volumes of tests for those analyses, with a positive effect on the amortization of their equipment purchase
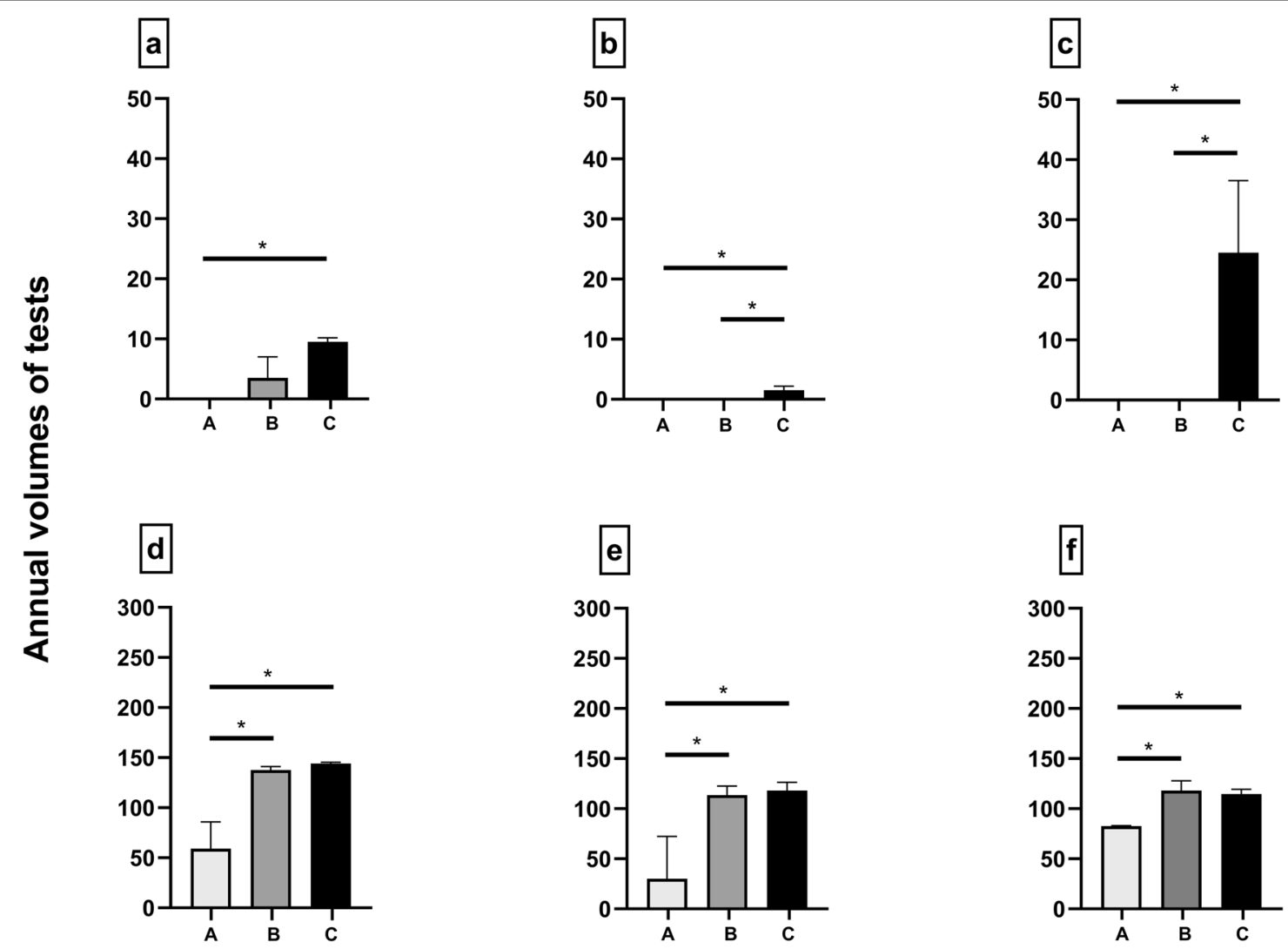

Before the feasibility study (data collected for 2014 and 2015)
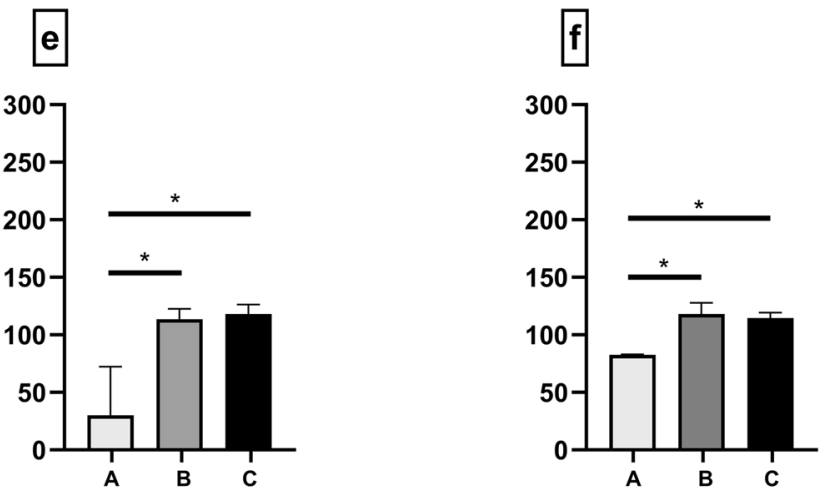

After the recognition of RLs (data collected for 2019 and 2020)

Fig. 6 Significant impact of the feasibility study results on the annual volumes of six analyses. Comparison of the volumes of tests reported by the Belgian laboratories of clinical pathology for 6 different years: group A (light grey bars, period before the presentation of the results of the feasibility study [data collected for 2014 and 2015]) versus group B (dark grey bars, period after the presentation of the results of the feasibility study [data collected for 2016 and 2017]) versus group C (black bars, period from RLs'recognition [data collected for 2019 and 2020]). Values were calculated as mean volumes $\pm S D, n=2$ for the 3 groups $(A, B, C)$ of two successive years. Statistical analyses were performed by one-way ANOVA with Tukey's posttest for multiple comparisons between the 3 groups. Asterisks indicate values that are statistically significantly different from each other $\left({ }^{*} p<0.05\right)$. Analyses presented in each panel: a assessment of a-aminoadipic semialdehyde and 81 -piperideine-6-carboxylate in urine; $\mathbf{b}$ assessment of B6 vitamers in plasma; c assessment of pterins in urine; $\mathbf{d}$ assessment of Complement component Factor B; e assessment of Complement component Factor Bb; $\mathbf{f}$ assessment of intra-leukocyte cystine. RLs Reference laboratories 
costs, analyses' validation costs and staff training costs. Figure 6 illustrates the comparison of the mean annual volumes collected for three different periods: before the presentation of the results of the feasibility study (group A, data collected for 2014 and 2015), after the presentation of the results of the feasibility study (group B, data collected for 2016 and 2017), and after the RLs' recognition (group C, data collected for 2019 and 2020). Results are expressed as mean volumes \pm SD for 2 successive years $(\mathrm{n}=2)$. For the 6 analyses shown in this figure, a significant increase $(p<0.05)$ of the mean annual volumes of tests could be observed after the presentation of the results of the feasibility study in 2016. This highlights the positive impact of this project on the development of new analyses in Belgium (panels $\mathrm{a}-\mathrm{c}$ ) but also on the performance of some other analyses available in Belgium since many years (panels $\mathrm{d}-\mathrm{f}$ ). For the other analyses performed by RLs, no statistically significant modification of the annual volumes could be observed between 2014 and 2020 (see Additional file 1: Figure S1). This may be explained by the very low prevalence of the diseases for which these analyses are prescribed and therefore the limited number of tests that makes the inter-groups differences less important.

\section{Follow-up of costs and expertise recognition}

An annual activity and financial report describing the activities, financing and renewal of the Belgian RLs of clinical pathology and the outsourcing of analyses to foreign laboratories will be annually sent to the INAMI-RIZIV.

\section{Discussion}

This study is the first Belgian initiative for the improvement of the management of patients with rare diseases through the promotion and financing of analyses of clinical pathology.

Its approach derives from the "RAND/UCLA appropriateness method", which aims to measure and validate the necessity and usefulness of clinical procedures based on the consensus of experts' opinions [21, 22].

Several inputs of this project are worth mentioning. First of all, this study enabled to create a permanent working group composed of Belgian experts in rare diseases management within the Belgian Commission on Clinical Pathology. This will help to perform a continuous follow-up of rare diseases diagnosis and epidemiology in Belgium and of the efficiency and quality of medical analyses performed in these particular contexts. Moreover, the collaboration between this working group and Sciensano enabled the (1) identification of unmet financing needs for specific analyses of clinical pathology used for rare diseases' diagnosis/ follow-up, (2) set-up of coverage of these tests by the Belgian Healthcare system, under the surveillance of Sciensano and INAMI-RIZIV, and (3) establishment of reference laboratories (RLs) for the most specific tests.

The establishment by the Belgian healthcare authorities of a specific budgetary envelop dedicated to analyses of clinical pathology supports the usefulness of these tests in the context of rare diseases diagnosis and follow-up in parallel with genetic tests.

Nowadays, RLs have been recognized for a few types of medical analyses and in a limited number of countries. Most of them are focused on human genetics and microbiology tests [23-25]. The establishment of Belgian RLs for some analyses used in the context of rare diseases performed during this study echoes the previous recognition of Belgian National Reference Centers for human microbiology in 2011 [24] and is to our knowledge the first RL initiative in the context of rare diseases and for analyses of clinical chemistry, haematology and immunology.

The RLs recognition offers several advantages in terms of healthcare quality. First, it took place after a harmonized selection procedure for all tests considered. Second, affiliations of RLs to university hospitals improves the clinical management of the patients with rare diseases due to the close link between clinical and laboratory activities and reduced TAT. Third, RLs possess a highly-specialized equipment and perform the analyses using validated methods based on peer-reviewed publications and international guidelines. Fourth, RLs annually participate to external quality controls for the test(s) for which their expertise has been recognized. Fifth, the centralization of highly-specific tests to one or two RL(s) is cost-effective regarding the amortization of laboratory costs related to the performance of small tests' annual volumes, as it is the case for rare diseases, and helps the prescribers to rapidly identify the RLs to which clinical samples have to be sent. Finally, RLs recognition and financing will also encourage the Belgian laboratories to develop and validate new tests that remain unavailable in Belgium.

In addition, the selection of RLs will have a positive impact on public health by offering useful expertise in rare diseases management to the medical authorities, healthcare professionals and patients and by helping to collect information about rare diseases in Belgium through national databases and registries.

Lastly, it is important to mention that recognition of RLs by the Belgian healthcare authorities gives the laboratory a particular visibility and notoriety at the national and international levels, and a responsibility in terms of healthcare excellence and scientific expertise. This helps RLs to expand their collaborations and to 
position themselves within the Rare Diseases European Reference Networks [26].

\section{Conclusions}

This initiative of the Belgian plan for rare diseases (1) promotes healthcare quality and the expertise recognition and collaborations of Belgian rare diseases experts at the national and international levels, (2) offers a better financing to the laboratories of clinical pathology performing highly-specific analyses in the context of rare diseases, and (3) enables to reduces patients' costs.

\section{Supplementary Information}

The online version contains supplementary material available at https://doi. org/10.1186/s13023-021-01728-1.

Additional file 1: Figure S1. Analyses for which the mean annual volumes were not modified by the feasibility study results. Comparison of the volumes of tests reported by the Belgian laboratories of clinical pathology for 6 different years: group A (light grey bars, period before the presentation of the results of the feasibility study [data collected for 2014 and 2015]) versus group B (dark grey bars, period after the presentation of the results of the feasibility study [data collected for 2016 and 2017]) versus group C (black bars, period from RLs' recognition [data collected for 2019 and 2020]). Values were calculated as mean volumes $\pm S D, n=2$ for the 3 groups $(A, B, C)$ of two successive years. Statistical analyses were performed by one-way ANOVA with Tukey's posttest for multiple comparisons between the 3 groups. The absence of asterisks indicates values that are not statistically significantly different from each other $(p \geq 0.05)$. Analyses presented in each panel: a: assessment of Complement component Factor D; b: assessment of Complement component Factor P; c: assessment of plasma porphobilinogen; d: fractionation of plasma porphyrins; e: assessment of the dihydropteridine reductase activity in dried blood spots; f: assessment of plasmalogen levels in red blood cells; g: cytogenetic radiosensitivity assay; h: assessment of 81 -piperideine-6-carboxylate in plasma; i: determination of 5-methyltetrahydrofolate in cerebrospinal fluid; j: analysis of the deformability of erythrocytes using osmotic gradient ektacytometry and separation of red blood cells membrane proteins by SDS-PAGE; k: assessment of free erythrocyte protoporphyrins; I: spectrofluorimetric assessment of plasma porphyrins. Abbreviations: RLs: Reference laboratories.

\section{Abbreviations}

BCCP: Belgian Commission on Clinical Pathology; EQA: External Quality Assessment; INAMI-RIZIV: National Institute for Health and Disability Insurance; RAND/UCLA: Research and Development/University of California, Los Angeles; RDWG: Rare Diseases Working Group; RL: Reference laboratory; SOP: Standard operating procedure; TAT: Turnaround time.

\section{Acknowledgements}

The authors thank the Belgian laboratories of clinical pathology who answered the survey, the Belgian Commission on Clinical Pathology working groups for their advisory support, Dr. Christel Van Campenhout (WIV-ISP) for her advices during the survey preparation, Drs. Chantal Mathy and Marc Moens (INAMI-RIZIV) for their help in the follow-up of proposals evaluation by the Belgian healthcare authorities.

\section{Authors' contributions}

NMV conceived the study, wrote the manuscript and created the tables and figures. All authors participated to the data collection. NMV, PV, KMJD, MFV, BG, $F E, F B, A G, V O V H, C B, H S, G A M, X B, L R$, JS and $H L$ analyzed the study data and developed the proposals of financing modalities for selected priority analyses. All authors contributed to the discussion and critically revised and edited the manuscript. Corrections and finalization of the manuscript were conducted in close exchange with all authors. All authors read and approved the final manuscript.

\section{Funding}

N.M.V is a scientific collaborator from the WIV-ISP/Sciensano and supported by the INAMI-RIZIV (Grants W4043.0100.5/W4043.0100.8).

\section{Availability of data and materials}

The data management is coordinated by Sciensano, Belgium based on rules consented by the participating institutions. Interested research groups may apply for access and permission to analyze data, within the legal and ethical framework, through the Secure File Transfer Protocol (SFTP). Applications should be directed to the principal investigator: nathalie.vandevelde@ sciensano.be.

\section{Ethics approval and consent to participate}

Not applicable.

\section{Consent for publication \\ Not applicable.}

\section{Competing interests}

The RDWG members involved in the priority analyses selection work in some of the laboratories performing the analyses covered in this paper.

\section{Author details}

1 Department of Quality of Laboratories, Sciensano, Rue Juliette Wytsmanstraat 14, 1050 Brussels, Belgium. ${ }^{2}$ Rare Diseases Working Group, Belgian National Commission on Clinical Pathology, Brussels, Belgium. ${ }^{3}$ Department of Laboratory Medicine, UZ Leuven, Leuven, Belgium. ${ }^{4}$ Department of Cardiovascular Sciences, University of Leuven, Leuven, Belgium. ${ }^{5}$ Department of Laboratory Medicine, Ghent University Hospital, Ghent, Belgium.

${ }^{6}$ Department of Laboratory Medicine, Cliniques Universitaires Saint-Luc and Université Catholique de Louvain, Brussels, Belgium. ${ }^{7}$ Belgian Fund Rare Diseases and Orphan Drugs, Brussels, Belgium. ${ }^{8}$ Clinical Pathology, LHUB-ULB, Université Libre de Bruxelles, Brussels, Belgium. ${ }^{9}$ Center of Inherited Metabolic Diseases, Antwerp University Hospital, Edegem, Belgium. ${ }^{10}$ Department of Metabolic Disorders in Children, Antwerp University Hospital, Edegem, Belgium. ${ }^{11}$ Observatory of Chronic Diseases, National Institute for Health and Disability Insurance (INAMI-RIZIV), Brussels, Belgium. ${ }^{12}$ Biochemical Genetics Lab, Department of Human Genetics, CHU of Liege, University of Liege, Liège, Belgium. ${ }^{13}$ Department of Laboratory Haematology and Immuno-Haematology, CHU Liège, Liège, Belgium. ${ }^{14}$ Department of Clinical Chemistry, Antwerp University Hospital, Edegem, Belgium. ${ }^{15}$ VUB Metabolomics Platform, Vrije Universiteit Brussel, Brussels, Belgium. ${ }^{16}$ Laboratory for Molecular Diagnostics, AZ Delta Roeselare, Roeselare, Belgium. ${ }^{17}$ Laboratory for TDM and Toxicology, University Hospital Antwerp, Edegem, Belgium. ${ }^{18}$ Laboratory of Pediatric Research, Free University of Brussels, Brussels, Belgium. ${ }^{19}$ Department of Clinical Chemistry and Radio-Immunology, University Hospital Brussels, Brussels, Belgium. ${ }^{20}$ Laboratory and Department of Blood Transfusion, CHR de la Citadelle, Liège, Belgium.

Received: 12 June 2020 Accepted: 3 February 2021

Published online: 17 February 2021

\section{References}

1. Rodwell C, Aymé S. Rare disease policies to improve care for patients in Europe. Biochim Biophys Acta. 2015;1852(10 Pt B):2329-35.

2. Dharssi S, Wong-Rieger D, Harold M, Terry S. Review of 11 national policies for rare diseases in the context of key patient needs. Orphanet J Rare Dis. 2017; 12:1-13.

3. Garau R. The medical experience of a patient with a rare disease and her family. Orphanet J Rare Dis. 2016;11:1-3.

4. Evangelista T, Hedley V, Atalaia A, Johnson M, Lynn S, Le Cam Y, et al. The context for the thematic grouping of rare diseases to facilitate the establishment of European Reference Networks. Orphanet J Rare Dis. 2016;11:1-8. 
5. Aymé S. State of the art of rare disease activities in Europe: a EUCERD perspective. Orphanet J Rare Dis. 2012;7(Suppl 2):A1.

6. Zurynski Y, Deverell M, Dalkeith T, Johnson S, Christodoulou J, Leonard H, et al. Australian children living with rare diseases: experiences of diagnosis and perceived consequences of diagnostic delays. Orphanet J Rare Dis. 2017;12:1-9.

7. Grier J, Hirano M, Karaa A, Shepard E, Thompson JLP. Diagnostic odyssey of patients with mitochondrial disease: results of a survey. Neurol Genet. 2018:4(2):e230.

8. Taruscio D, Gentile AE, De Santis M, Ferrelli RM, Posada de la Paz M, Hens M, et al. EUROPLAN: a project to support the development of national plans on rare diseases in Europe. Public Health Genomics. 2013;16(6):278-87.

9. Council of the European Union. Council Recommendation on action in the field of rare diseases. 2947th Employment, social policy, health and consumer affairs Council meeting, Luxembourg; 2009. https://www.consi lium.europa.eu/uedocs/cms_data/docs/pressdata/en/lsa/108383.pdf. Accessed 28 Aug 2019.

10. Onkelinx L. Plan belge pour les Maladies Rares. 2013. https://www.healt h.belgium.be/sites/default/files/uploads/fields/fpshealth_theme_file/ plan_belge_maladies_rares.pdf. Accessed 22 Aug 2019.

11. Gülbakan B, Özgül RK, Yüzbaşıoğlu A, Kohl M, Deigner H-P, Özgüç M. Discovery of biomarkers in rare diseases: innovative approaches by predictive and personalized medicine. EPMA J. 2016;7(1):1-6.

12. Orphanet [Internet]. https://www.orpha.net/. Accessed 6 Dec 2020.

13. McKillop DJ, Auld P. National turnaround time survey: professional consensus standards for optimal performance and thresholds considered to compromise efficient and effective clinical management. Ann Clin Biochem. 2017;54(1):158-64.

14. van den Oever R, Volckaert C. Financing health care in Belgium. The nomenclature: from fee-for-service to budget-financing. Acta Chir Belg. 2008;108(2):157-66

15. Van Baelen L, Antoine J, De Ridder K, Muyldermans G, Gremeaux L. Diagnostic hepatitis $C$ testing of people in treatment for substance use disorders in Belgium between 2011 and 2014: a cross-sectional study. Acta Gastroenterol Belg. 2019;82(1):35-42.

16. Van de Voorde C, Van den Heede K, Obyn C, Quentin W, Geissler A, Wittenbecher F, et al. KCE Report 229 Health Services Research-Conceptual framework for the reform of the Belgian hospital payment system. 2014 https://www.absym-bvas.be/images/Kce/KCE/KCE_229_Hospital_Finan cing_Report.pdf. Accessed 23 Aug 2019.

17. Daubie M. Soins de Santé-Circulaire OA no 2019/347 du 23 décembre 2019-Tarifs; médecins_biologie clinique; 01-01-2020. INAMI-RIZIV; 2019. https://www.absym-bvas.be/images/nomenclature/Honoraires _INAMI_2020/BioClin_20200101.pdf. Accessed 1 Sept 2020.

18. Belgian Monitor. 2019/40492-Arrêté royal modifiant les articles 3, § $1 \mathrm{er}$, A et $\mathrm{C}$, et 24, $\$ 1 \mathrm{er}$, de l'annexe à l'arrêté royal du 14 septembre
1984 établissant la nomenclature des prestations de santé en matière d'assurance obligatoire soins de santé et indemnités - Koninklijk besluit tot wijziging van de artikelen $3, \S 1$, A en C, en 24, § 1, van de bijlage bij het koninklijk besluit van 14 september 1984 tot vaststelling van de nomenclatuur van de geneeskundige verstrekkingen inzake verplichte verzekering voor geneeskundige verzorging en uitkeringen. 2019;(2019040610):19862-8.

19. Belgian Monitor. 99/24072-Arrêté royal relatif à l'agrément des laboratoires de biologie clinique par le Ministre qui a la Santé publique dans ses attributions. - Koninklijk besluit betreffende de erkenning van de laboratoria voor klinische biologie door de Minister tot wiens bevoegdheid de Volksgezondheid behoort. 1999;(1999024072):50217-31.

20. International Organization for Standardization. ISO 15189:2012 Medical laboratories-Requirements for quality and competence [Internet]. The International Organization for Standardization; 2012. https://www.iso. org/obp/ui/\#iso:std:iso:15189:ed-3:v2:en. Accessed 29 Aug 2019.

21. Nair R, Aggarwal R, Khanna D. Methods of formal consensus in classification/diagnostic criteria and guideline development. Semin Arthritis Rheum. 2011;41(2):95-105.

22. Fitch K, Bernstein SJ, Aguilar MD, Burnand B, LaCalle JR, Lázaro P, et al. The RAND/UCLA Appropriateness Method User's Manual [Internet]. RAND 1700 Main Street, P.O. Box 2138, Santa Monica, CA 90407-2138 1200 South Hayes Street, Arlington, VA 22202-5050 RAND. http://www. rand.org; 2001. https://www.rand.org/content/dam/rand/pubs/monog raph_reports/2011/MR1269.pdf. Accessed 22 Aug 2019.

23. Miller CE, Krautscheid P, Baldwin EE, TvrdikT, Openshaw AS, Hart K, et al. Genetic counselor review of genetic test orders in a reference laboratory reduces unnecessary testing. Am J Med Genet. 2014;164(5):1094-101.

24. Muyldermans G, Litzroth A, Ducoffre G, Quoilin S. Establishment and reinforcement of the national reference centers for human microbiology in Belgium. Arch Public Health. 2012;70(1):16.

25. Mögling R, Zeller H, Revez J, Koopmans M, Reusken C. Status, quality and specific needs of Zika virus (ZIKV) diagnostic capacity and capability in National Reference Laboratories for arboviruses in 30 EU/EEA countries, May 2016. Euro Surveill. 2017;22(36):30609.

26. European Union. European Reference Networks. Working for patients with rare, low-prevalence and complex diseases Share.Care.Cure. Publications Office of the European Union; 2017. https://ec.europa.eu/health/ sites/health/files/ern/docs/2017_brochure_en.pdf. Accessed 22 Aug 2019.

\section{Publisher's Note}

Springer Nature remains neutral with regard to jurisdictional claims in published maps and institutional affiliations.
Ready to submit your research? Choose BMC and benefit from:

- fast, convenient online submission

- thorough peer review by experienced researchers in your field

- rapid publication on acceptance

- support for research data, including large and complex data types

- gold Open Access which fosters wider collaboration and increased citations

- maximum visibility for your research: over $100 \mathrm{M}$ website views per year

At BMC, research is always in progress.

Learn more biomedcentral.com/submissions 